\title{
Expression patterns of ciliopathy genes ARL3 and CEP120 reveal roles in multisystem development
}

\author{
L. Powell ${ }^{1 \dagger}$, M. Barroso-Gil ${ }^{1 \dagger}$, G. J. Clowry², L. A. Devlin', E. Molinari ${ }^{1}$, S. A. Ramsbottom ${ }^{1}$, C. G. Miles ${ }^{1}$ and \\ J. A. Sayer ${ }^{1,3,4^{*}}$ iD
}

\begin{abstract}
Background: Joubert syndrome and related disorders (JSRD) and Jeune syndrome are multisystem ciliopathy disorders with overlapping phenotypes. There are a growing number of genetic causes for these rare syndromes, including the recently described genes ARL3 and CEP120.

Methods: We sought to explore the developmental expression patterns of ARL3 and CEP120 in humans to gain additional understanding of these genetic conditions. We used an RNA in situ detection technique called RNAscope to characterise ARL3 and CEP120 expression patterns in human embryos and foetuses in collaboration with the MRC-Wellcome Trust Human Developmental Biology Resource.

Results: Both ARL3 and CEP120 are expressed in early human brain development, including the cerebellum and in the developing retina and kidney, consistent with the clinical phenotypes seen with pathogenic variants in these genes.
\end{abstract}

Conclusions: This study provides insights into the potential pathogenesis of JSRD by uncovering the spatial expression of two JSRD-causative genes during normal human development.

Keywords: CEP120, ARL3, Foetus, Development, Retina, Kidney, Brain, RNAscope

\section{Background}

Joubert syndrome and related disorders (JSRD) are a group of autosomal inherited ciliopathies that are characterised as a cerebello-retinal-renal phenotype, and have an incidence rate of 1:80,000-100,000 live births [1-3]. The hallmark brain phenotype is a "molar tooth sign" shown on axial brain MRI, caused by cerebellar vermis hypoplasia and other mid and hindbrain

\footnotetext{
* Correspondence: john.sayer@newcastle.ac.uk

${ }^{+}$Powell $L$ and Barroso-Gil $M$ are joint first authors

${ }^{\dagger} \mathrm{L}$. Powell and M. Barroso-Gil contributed equally to this work.

${ }^{1}$ Translational and Clinical Research Institute, Newcastle University, Central Parkway, Newcastle upon Tyne NE1 3BZ, UK

${ }^{3}$ The Newcastle Hospitals NHS Foundation Trust, Freeman Road, Newcastle upon Tyne NE7 7DN, UK

Full list of author information is available at the end of the article
}

malformations [4]. These defects often cause symptoms of hypotonia, ataxia and intellectual disability in patients [5]. The retinal and renal phenotypes associated with JSRD have a lower incidence rate and vary in severity. Renal disorders occur in $\sim 25 \%$ of patients, often presenting as corticomedullary cysts, interstitial fibrosis, or tubulointerstitial kidney disease [5]. The renal component is progressive and can lead to end-stage renal disease [6]. Ocular phenotypes of retinitis dystrophy, retinitis pigmentosa, oculomotor apraxia, and ptosis are common in patients, and as with the renal aspects of JSRD are often progressive in nature [7].

Currently, there are more than 35 genes that are known to cause JSRD (https://www.omim.org/phenotypicSeries/PS213300). The syndrome is caused by defects

(c) The Author(s). 2020 Open Access This article is licensed under a Creative Commons Attribution 4.0 International License, which permits use, sharing, adaptation, distribution and reproduction in any medium or format, as long as you give appropriate credit to the original author(s) and the source, provide a link to the Creative Commons licence, and indicate if changes were made. The images or other third party material in this article are included in the article's Creative Commons licence, unless indicated otherwise in a credit line to the material. If material is not included in the article's Creative Commons licence and your intended use is not permitted by statutory regulation or exceeds the permitted use, you will need to obtain permission directly from the copyright holder. To view a copy of this licence, visit http://creativecommons.org/licenses/by/4.0/. The Creative Commons Public Domain Dedication waiver (http://creativecommons.org/publicdomain/zero/1.0/) applies to the data made available in this article, unless otherwise stated in a credit line to the data. 
of the primary cilia, which are found on most mammalian cells [8]. Primary cilia act as a cellular antenna to transduce extracellular signals such as mechanical flow, chemical stimulation, and key signalling pathways (including Hedgehog, Wnt, and PDGF) into the cell [913]. Due to the multi-organ involvement, varying phenotypes, and multitude of genes known to cause JSRD there is great heterogeneity within the syndrome and overlap with closely related ciliopathies including Bardet-Biedl syndrome (https://omim.org/phenotypicSeries/PS209900) and Jeune syndrome (https://omim. org/phenotypicSeries/PS208500) [14]. Recently discovered genetic causes of JSRD include ARL3 [15] and CEP120 [16, 17]; the fact that their encoded proteins have such divergent roles within the primary cilium demonstrates the complexity underlying this group of related disorders.

ADP-ribosylation factor-like 3 (ARL3), a RAS superfamily member, is a low molecular weight GTP-binding protein [18] that cycles between inactive GDP-bound and active GTP-bound states to release cargo from their carriers in the cilium [19]. ARL3 interacts with its Guanine Exchange Factor ARL13B in the cilium [20] and GTPase Activating Protein RP2 at the basal body of the cell [21, 22]. Arl3 knockout studies in mice demonstrate a multi-organ ciliopathy phenotype, including kidney cysts, liver fibrosis and retinal disease with photoreceptor cell degeneration [23-26]. Recently, two families affected by JSRD have been identified, presenting with ciliopathy phenotypes [15]. The underlying genetic cause was shown to be missense mutations in $A R L 3$, which affect an amino acid residue involved in the interaction between ARL3 and ARL13B [15].

Centrosomal protein of $120 \mathrm{kDa}$ (CEP120) is a centrosomal protein involved in centriole biogenesis, including centriole duplication, assembly [27, 28], elongation [2931] and maturation [28]. CEP120 also interacts with other centrosomal proteins including CPAP [29, 30], SPICE1 [29], Talpid3 [28, 31] and C2CD3 [31]. CEP120 was found to be expressed ubiquitously in murine embryonic tissues such as the brain, kidney and lungs. Additionally, Cep120 was observed to be highly expressed in embryonic mouse brain compared to postnatal or adult mouse brain [32]. Inactivation of CEP120 in the mouse central nervous system results in hydrocephalous and cerebellar hypoplasia [28]. CEP120 mutations have been shown to cause JSRD and Jeune syndromes [16, 17], and overlapping ciliopathy phenotypes such as tectocerebellar dysraphia with occipital encephalocele (TCDOE), Meckel syndrome (MKS) and oro-facial-digital (OFD) syndromes [17].

The developmental expression patterns of $A R L 3$ and CEP120 in humans is not known. In order to explore this, we used an RNA in situ detection technique called
RNAscope to compare and contrast the developmental spatial expression of these new and divergent causes of JSRD. We successfully characterised ARL3 and CEP120 expression patterns in human embryos and foetuses in collaboration with the MRC-Wellcome Trust Human Developmental Biology Resource (HDBR). This study provides insights into the potential pathogenesis of JSRD by uncovering the expression pattern of two JSRDcausative genes during normal human development.

\section{Methods \\ RNAscope studies}

Characterisation of ARL3 and CEP120 expression patterns was performed in human embryonic tissue using samples obtained from the MRC-Wellcome HDBR. Formalin fixed paraffin embedded sections of human embryonic and foetal tissue were prepared using 10\% neutral buffered formalin and fixed for $32 \mathrm{~h}$ at room temperature. Samples were then prepared for the RNAscope assay, a RNA in situ detection platform for detection of target RNA within intact cells, as per manufacturers' instructions [33, 34]. An RNAscope 2.5 Assay RED was employed with 20 paired probes across nucleotides 169-1570 (NM_004311.3) and 115-1133 (NM_001166226.1) for detection of ARL3 and CEP120, respectively and counterstained with Methyl Green.

Whole human embryo sections of 8 post-conception weeks (PCW), (equivalent to Carnegie Stage 23) were analysed, along with hindbrain (14PCW and 19PCW), eye $(14 \mathrm{PCW})$, kidney and adrenal gland (14PCW and 18PCW). A negative RNAscope 2.5 HD Assay Red control ( $\operatorname{dapB}$, a bacterial gene which is not expressed in human tissues) was performed (Supplementary Figure 1). In addition, the RNAscope $2.5 \mathrm{HD}$ Assay RED was performed with a positive control (KI67, a cell proliferation marker). KI67 is a nuclear protein commonly used as a proliferation marker, which is expressed in cycling cells and is associated with cellular proliferation. It is encoded by the gene marker of proliferation Ki-67, MKI67. ARL3 and CEP120 human expression patterns were analysed using the HDBR image server (Leica Biosystems).

\section{Clinical phenotypes and sequence analysis}

Reported clinical phenotypes associated with ARL3 and CEP120 mutations were reviewed within OMIM (https://omim.org/). Putative Arl3 and Cep120 orthologues were identified using BLASTP, with human ARL3 (isoform a, NP_004302.1) and CEP120 (NP_694955.2) transcripts as the query sequences within NCBI (https:// www.ncbi.nlm.nih.gov/). Additional databases including Flybase https://flybase.org/), Wormbase (https://www. wormbase.org/) and Phytozome (https://phytozome.jgi. doe.gov/) were also queried using BLAST. 


\section{Results}

Clinical phenotypes of ARL3 and CEP120 patients

Biallelic mutations in both ARL3 and CEP120 mutations are rare causes of ciliopathy syndromes. A comparison of the known phenotypes associated with $A R L 3$ and CEP120 mutations is shown in Table 1 . This overview reveals that mutations in CEP120 are at present associated with severe phenotypes including MKS but also that single heterozygous changes in $A R L 3$ are sufficient to cause retinal-limited phenotypes. $A R L 3$ is highly conserved, with homologs present in C. elegans, C. reinhardtii and D. melanogaster whereas CEP120 appears not to have homologs within these lower organisms (Supplementary Table 1). Known protein localisation within the cell of both ARL3 within the ciliary axoneme, and CEP120 in the centrosomes, are consistent with their role in ciliopathy syndromes (Supplementary Table 2).

\section{ARL3 and CEP120 are expressed in early human brain development}

In $8 \mathrm{PCW}$ human brain tissue, the expression of $A R L 3$ and CEP120 is remarkably similar. There is expression of both genes in the choroid plexus (Fig. 1Ai and 1Bi), which appears to favour the luminal facing surface of the tissue, especially for $A R L 3$. The cell proliferation marker KI67 does not share this same expression pattern in the choroid plexus (Fig. $1 \mathrm{Ci}$ ). This specific expression pattern of ARL3 and CEP120 in luminal-facing cells is continued throughout the developing brain where both genes exhibit expression throughout the ventricular zone of the ganglionic eminences, cortical wall, and the hindbrain including the rhombic lip (Fig. 1Aii-Aiv and 1BiiBiv). There is specific expression of ARL3 and CEP120 in the layer of cells forming the apical surface in each tissue, facing into the ventricular space. Expression of KI67 is seen throughout these tissues (Fig. 1Cii-Civ), with specific expression in the apical layer consistent with this being the major site of cell division (cells in G2/M1 phase of cell cycle) in the ventricular zone [37].

\section{Expression of ARL3 and CEP120 is maintained in the developing cerebellum}

In the human cerebellum at 14PCW there is expression of $A R L 3$ and CEP120. Both genes have strong expression in the external and internal granule cell layer (EGL and IGL) the developing cerebellum (Fig. 2Ai and Ci). Expression in the EGL and IGL is seen at 19PCW for ARL3 (Fig 2Bi) however, CEP120 expression is predominantly localised in the EGL and the molecular layer (ML) of the cerebellum at 19PCW (Fig. 2Di). Strong expression of KI67 is seen throughout the EGL in particular, but also the IGL at 19PCW, indicating the tissue is proliferative (Fig. 2Ei). ARL3 and CEP120 are therefore widely expressed in the cerebellum during development, with specific expression of CEP120 in the ML which is

Table 1 Comparison of the known phenotypes associated with ARL3 and CEP120 mutations

\begin{tabular}{|c|c|c|}
\hline & Patients with $A R L 3$ related ciliopathy & $\begin{array}{l}\text { Patients with CEP120 related } \\
\text { ciliopathy }\end{array}$ \\
\hline $\begin{array}{l}\text { Number of affected patients reported and } \\
\text { presenting phenotypes }\end{array}$ & $\begin{array}{l}4 \text { patients reported with JSRD secondary to biallelic } \\
\text { changes }[15] \\
4 \text { patients with retinitis pigmentosa secondary to } \\
\text { monoallelic changes }[35,36]\end{array}$ & $\begin{array}{l}4 \text { patients with JSRD } \\
4 \text { patients with JATD } \\
1 \text { foetus with MKS } \\
1 \text { foetus with TCDOE } \\
{[16,17]}\end{array}$ \\
\hline Brain imaging findings & Molar tooth sign & Molar tooth sign \\
\hline Intellect & $\begin{array}{l}\text { Developmental delay } \\
\text { Psychomotor delay }\end{array}$ & $\begin{array}{l}\text { Developmental delay } \\
\text { Cognitive impairment }\end{array}$ \\
\hline Skeletal & No known associated phenotypes & $\begin{array}{l}\text { Severely narrow chest } \\
\text { Skeletal dysplasia } \\
\text { Small and horizontal ribs } \\
\text { Short limbs } \\
\text { Polydactyly } \\
\text { Synpolydactyly }\end{array}$ \\
\hline Mobility & $\begin{array}{l}\text { Ataxic gait } \\
\text { Hypotonia }\end{array}$ & $\begin{array}{l}\text { Truncal ataxia } \\
\text { Hypotonia }\end{array}$ \\
\hline Eye & $\begin{array}{l}\text { Night blindness } \\
\text { Bilateral vision loss } \\
\text { Retinal dystrophy } \\
\text { Ocular motor apraxia }\end{array}$ & $\begin{array}{l}\text { Microphthalmia } \\
\text { Duane syndrome } \\
\text { Strabismus }\end{array}$ \\
\hline Kidney & $\begin{array}{l}\text { Cystic dysplastic kidney } \\
\text { Bilateral renal scarring } \\
\text { Recurrent urinary tract infections }\end{array}$ & Cystic dysplastic kidney \\
\hline
\end{tabular}

JSRD Joubert syndrome and related disorders; JATD Jeune asphyxiating thoracic dystrophy; MKS Meckel syndrome; TCDOE tectocerebellar dysraphia with occipital encephalocele 

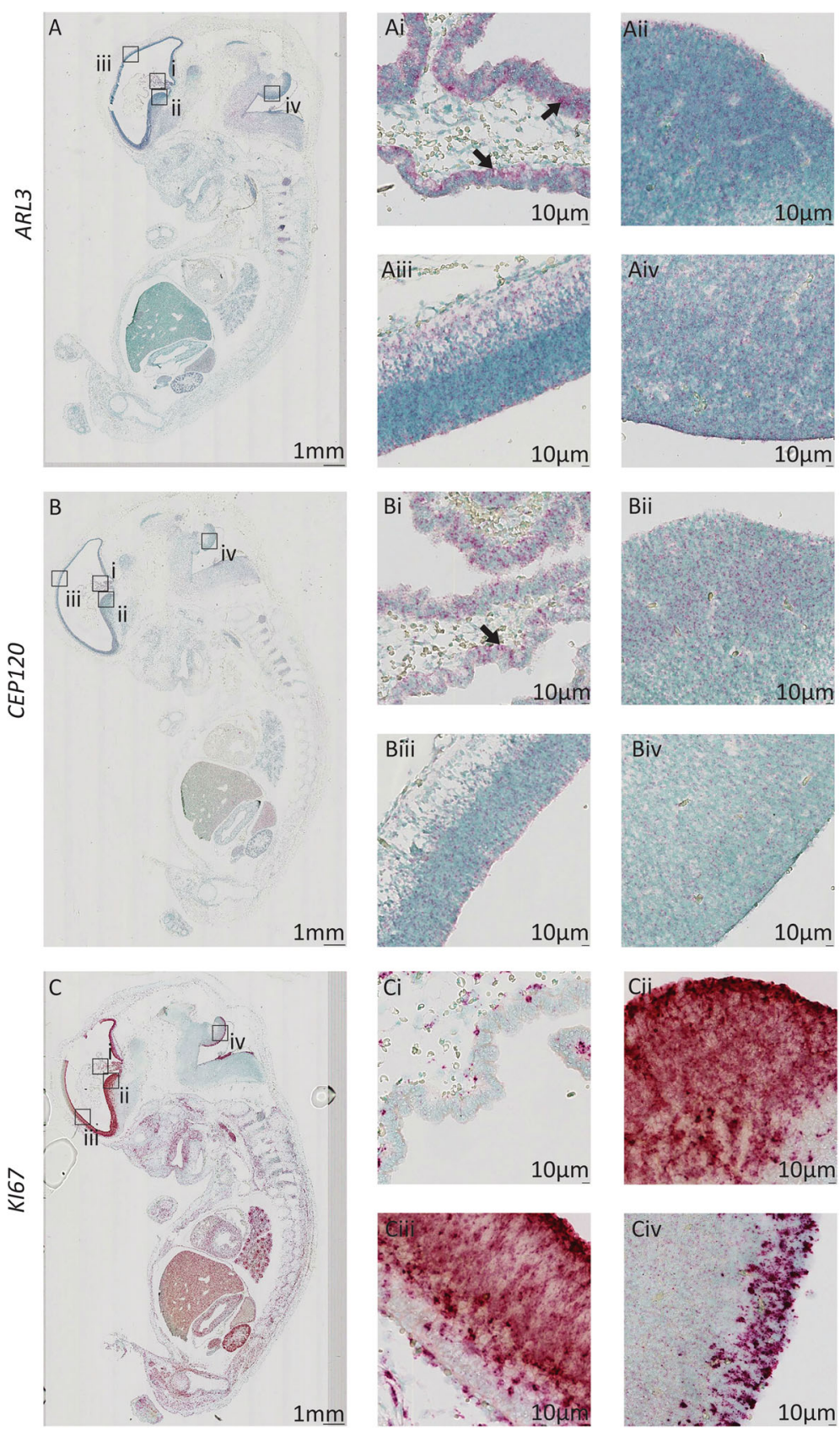

Fig. 1 Expression pattern of ARL3 and CEP120 in the human brain during early development. Sagittal sections of 8PCW-stage human embryos stained using RNAscope to show expression of ARL3 (a) (red), CEP120 (b) (red) and KI67 (c) (red), counterstained with Methyl Green. Ai and $\mathbf{B i}$ ARL3 and CEP120 are expressed within cells of the choroid plexus (arrow). (Ci) K167 expression is minimal in the choroid plexus. Aii-Aiv and (BiiBiv) Expression of ARL3 and CEP120 is seen in the ventricular radial glia progenitor cells including the ventricular zone of the ganglionic eminences (Aii and Bii), cerebral cortex (Aiii and Biii), and rhombic lip (Aiv and Biv). Cii-Civ Expression of KI67 is seen in the ventricular zone of the ganglionic eminences, cerebral cortex, and hindbrain

predominantly occupied by the dendritic trees of Purkinje cells and the interacting parallel fibres of granule cells. As dendrites and axons contain low levels of mRNA, it is likely that CEP120 expression is predominantly located in the sparse population of interneurons found in the molecular layer [38] or in immature granule cells migrating from EGL to IGL [39] suggesting a role for CEP120 in these cell types [38].

\section{Expression of ARL3 and CEP120 in the developing eye}

The human retina can be divided into nine layers based upon the cell types that occupy each layer 


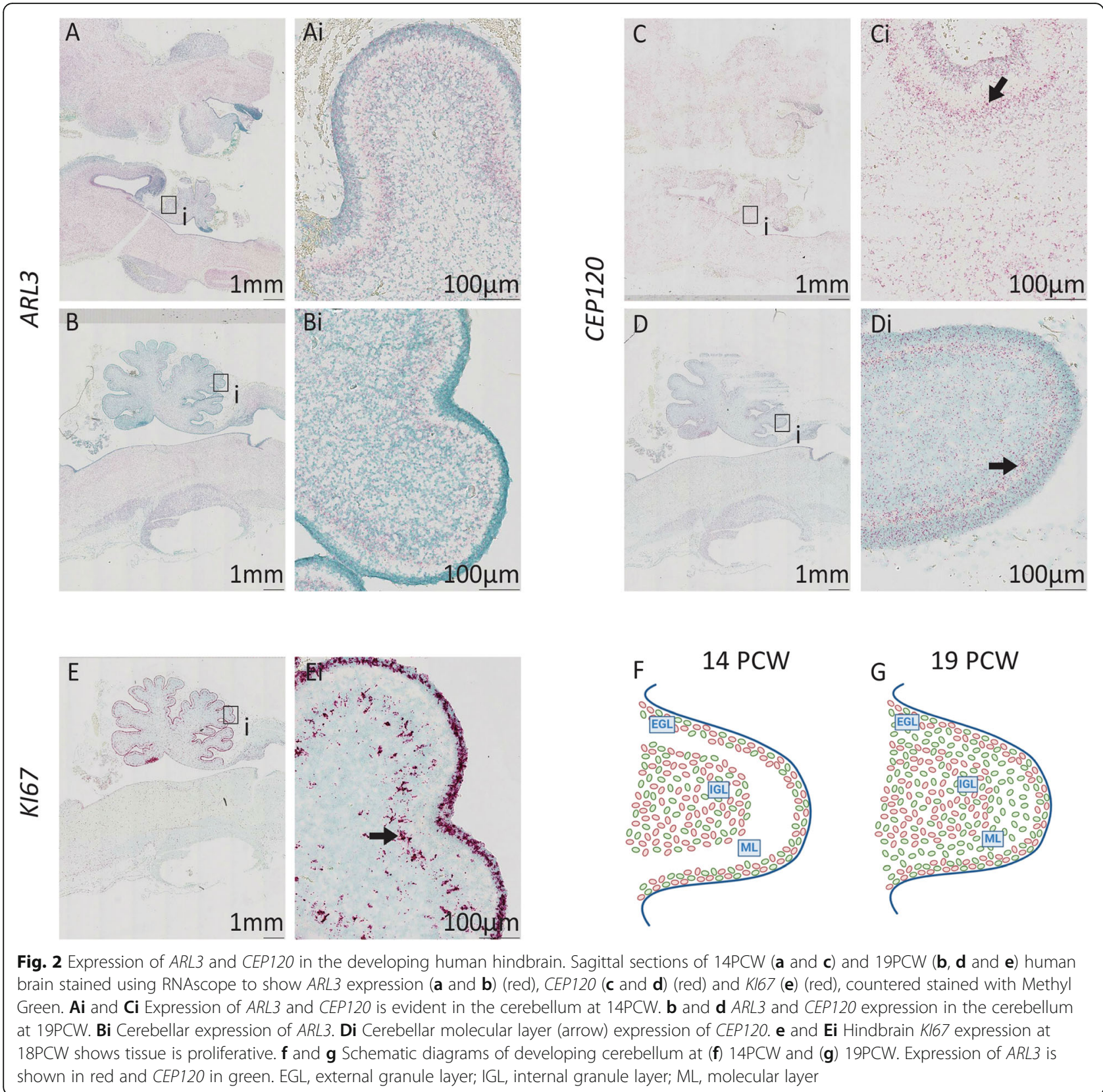

(Fig. 3a), with the retinal pigment epithelial (RPE) and photoreceptor layers at the outermost part of the eye [39]. At $8 \mathrm{PCW}$, the retinal layers are not well defined with only a ganglion cell layer separated from a layer of mostly immature neuroblasts with a few photoreceptor cells by a thin inner plexiform layer [40]. At this stage ARL3 and CEP120 show expression throughout the developing retina, with high expression within the retinal ganglion cells and the photoreceptor layer (Fig. 3Bi and $\mathrm{Di}$ ). At 14PCW, the retinal layers are maturing [39] which is reflected in the expression pattern of both ARL3 and CEP12O. Clear expression of both genes is still seen in all layers of the retina, although to a lesser extent in the plexiform and nerve fibre layers due to reduced cell density in these areas (Fig. $3 \mathrm{Ci}$ and $\mathrm{Ei}$ ).

\section{Expression of ARL3 and CEP120 in the developing dorsal root ganglia}

The dorsal root ganglia are formed by migrating neural crest cells and contain most of the body's sensory neurones [42, 43]. Both ARL3 and CEP120 show expression in cells of the dorsal root ganglia, which are post-mitotic primary sensory neurons (Fig. 4 Ai-Aii and Bi-Bii). There is strong expression of KI67 within limited 

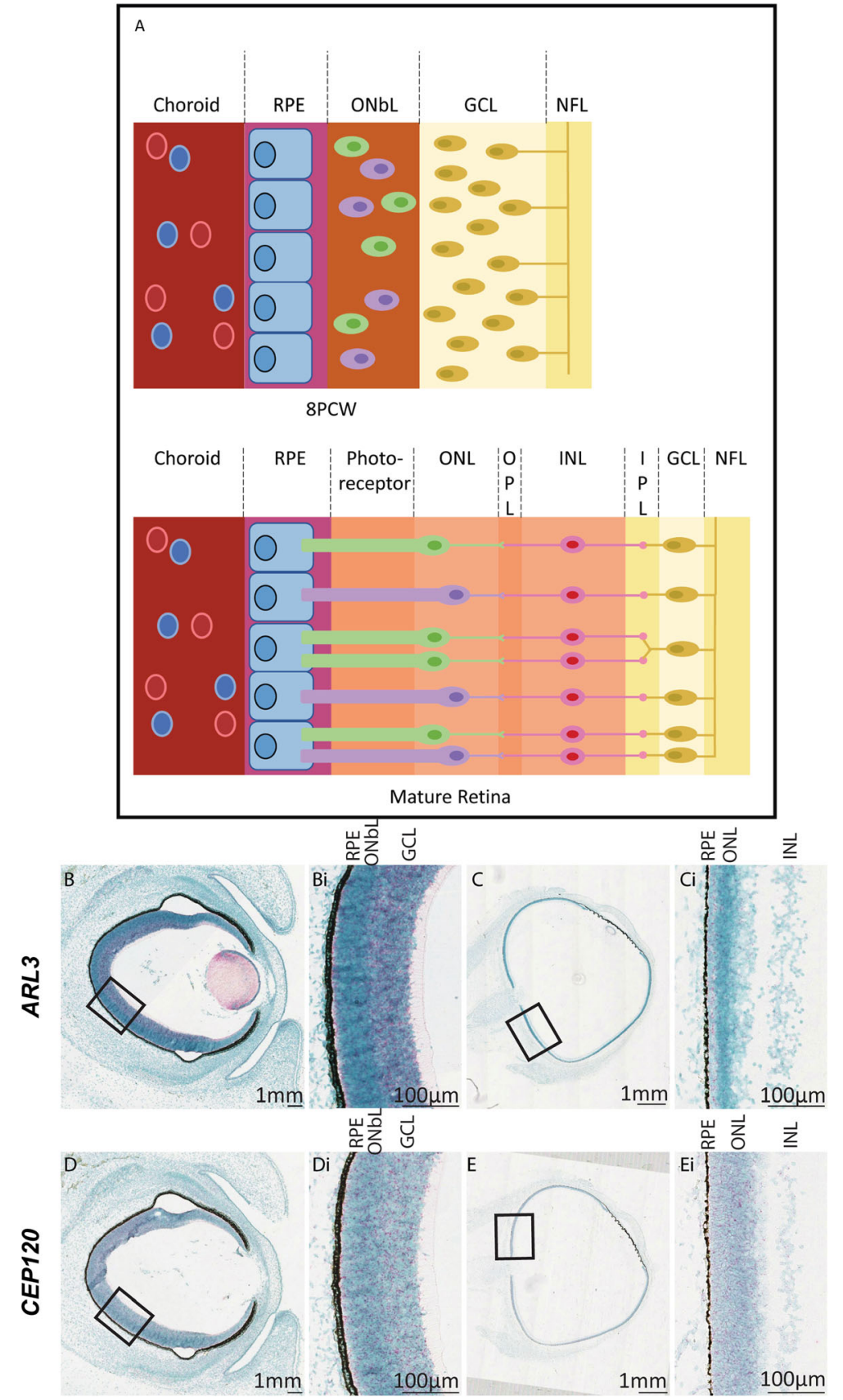

Fig. 3 Expression of ARL3 and CEP120 in the developing human retina. a Schematic diagram of the development of the layers of the retina from $8 \mathrm{PCW}$ to the mature form (adapted from [40]). At 8PCW, not all of the layers are present in the retina. The ONbL is a transitionary layer containing retinal progenitor cells that will develop into various cell types such as photoreceptors, amacrine and bipolar cells; separating into the ONL, OPL, INL, and IPL (the IPL is sometimes visible at 8PCW). The GCL is thicker at 8PCW due to the migration of cells. The mature retina can be divided into layers. The RPE is at the very back of the eye and assists in the removal of waste products from the photoreceptor cells, which transduce light. The ONL, OPL, INL and IPL layers house intermediary cell bodies and dendrites that interact with ganglion cells in the GCL to convey the signal through the optic nerve, formed in the NFL, to the brain (reviewed in [41]). b Human sections of developing eye at 8PCW (b and $\mathbf{d}$ ) and 14PCW (c and e) stained using RNA Scope to show ARL3 expression (b and $\mathbf{c}$ ) (red) and CEP120 (d and e) (red) counterstained with Methyl Green $(\mathbf{B i}$ and $\mathbf{D i})$. There is a gradient of ARL3 (Bi) and CEP120 (Di) expression in the retina at 8PCW across multiple retinal layers including the ONbL. At 14 PCW, ARL3 (Ci) and CEP120 (Ei) expression is localised across multiple layers including the photoreceptor cell layer, just below the RPE layer (arrows). GCL, ganglion cell layer; INL, inner nuclear layer; IPL, inner plexiform layer; NFL, nerve fibre layer; ONL, outer nuclear layer; OPL, outer plexiform layer; ONbL, outer neuroblastic layer; RPE, retinal pigment epithelium 
number of cells in the dorsal root ganglia, presumably non-neuronal (Fig. 4 Ci-Cii).

\section{Expression of ARL3 and CEP120 in the developing kidney} In the developing human kidney at $8 \mathrm{PCW}$, where there is strong renal cortical staining of KI67 indicating cell proliferation (Supplementary Figure 2), there is expression of ARL3 in cells within the developing cortical nephrons; this expression appears to be specifically oriented to the lumen of the structures (Fig. 5Ai). This expression pattern is maintained at 14PCW (Fig. 5Bi) and $18 \mathrm{PCW}$ (Fig. $5 \mathrm{Ci}$ ). Expression of CEP120 is also seen in developing nephrons at $8 \mathrm{PCW}$, however there is also expression in the renal cortex (Fig. 5Di). This expression pattern of CEP120 is maintained at $14 \mathrm{PCW}$ (Fig. 5Ei) and $18 \mathrm{PCW}$, although overall expression appears to have decreased at this time point (Fig. 5Fi).

\section{Expression of ARL3 and CEP120 in other major organs}

In the developing human heart, lung and gut at $8 \mathrm{PCW}$, there is very low levels of expression of $A R L 3$ and CEP120 (Supplementary Figure 3). Expression of ARL3 and CEP120 is seen around the developing alveoli and at low levels in the developing bowel epithelia. The remaining organs of the developing embryo did not reveal prominent expression patterns.

\section{Discussion}

Mutations in ARL3 and CEP120 are rare and relatively new causes of JSRD and other related ciliopathies. Human protein atlas data suggests that tissue expression of ARL3 protein is widely expressed, with highest expression scores seen in cerebellum and lowest in heart and skeletal muscle (https://www.proteinatlas.org/ENSG00000138175-ARL3/tissue). RNA expression is high in cerebral cortex, cerebellum, retina and kidney consistent with its known phenotypes. CEP120 protein expression is not annotated within the human protein atlas, whereas RNA is strongly expressed in the cerebellum (https://www.proteinatlas.org/ENSG00000168944-CEP120/tissue). We aimed to define expression of ARL3 and CEP120 during human development using the HDBR tissue bank employing a relatively new in situ hybridisation assay called RNAscope for the detection of target RNA within intact cells. We used KI67 as a positive control although we recognise that expression of $K I 67$ is not homogeneous throughout each tissue. Our data provide an insight into the developmental expression of ARL3 and CEP120. We show that both of these genes are expressed in key tissues (including retina, cerebellum and kidney) during development. This expression pattern fits with the multisystem disease phenotypes seen in patients with ARL3 and CEP120 mutations (Table 1). A similar approach, using the valuable HDBR tissue bank has been performed, using in situ hybridisation for studying the expression of $A R L 13 B$ [44], another cause of Joubert syndrome. Here $A R L 13 B$ was detected at stage CS16 in the alar and basal plate of the myelencephalon, the mesencephalon and the metencephalon. At CS19 $A R L 13 B$ was seen in the ventricular layer of the diencephalon and myelencephalon, the tegmentum of the pons and the cerebellar rhombic lips as well as the dorsal root ganglia. This pattern of expression is remarkably similar to the CEP120 and ARL3 data described here.

Expression of both ARL3 and CEP120 was minimal in developing cardiac, lung and gut tissues, consistent with lack of known phenotypes affecting these organ systems (Supplementary Figure 3). ARL3 and CEP120 encode proteins that are expressed in the primary cilia and basal body respectively (Supplementary Table 2) and pathogenic variants result in similar and overlapping phenotypes, including the cerebello-retinal-renal syndrome JSRD (Table 1). The number of patients with pathogenic variants in either ARL3 or CEP120 remains small, allowing a limited comparison of phenotypes, although skeletal manifestations (in particular short ribs/asphyxiating thoracic dystrophy phenotypes) seen in patients with CEP120 mutations have not been documented in patients with $A R L 3$ mutations.

There were notable differences in evolutionary conservation between $A R L 3$ and CEP120 (Supplementary Table 1). The ARL3 human protein shares greater than $90 \%$ identity with its two orthologous sequences (there is genomic duplication of arl3) in Danio renio (zebrafish), a well-studied model species in vertebrates. In contrast, CEP120 human protein only shares $57 \%$ identity with its single orthologous sequence found in zebrafish. Moreover, human ARL3 protein shares $>60 \%$ identity with its orthologues found in Drosophila melanogaster, Caenorhabditis elegans and Chlamydomonas reinhardtii. CEP120 is conserved in some vertebrate organisms but orthologues were not readily identified in invertebrates. There is a putative CEP120 orthologue, UNI2, found in Chlamydomonas reinhardtii, but this has not as yet been confirmed as a functional ortholog [27, 44]. ARL3 is described in diverse eukaryotic organisms such as Leishmania donovani [45] and Caenorhabditis elegans [46] [47] where it has a functional role in the cilium/flagella. Despite these differences in evolutionary conservation, our results show that ARL3 and CEP120 have similar expression patterns during human development, specifically in the eye and dorsal root ganglia as well as during early brain development. Both genes are expressed throughout the retina during development, with expression in the RPE and photoreceptor layers, suggesting a role for both genes during retinal development. This is further supported by the numerous retinal phenotypes associated with mutations in ARL3 [15-17]. Similarly, the specific expression of $A R L 3$ and CEP120 in 

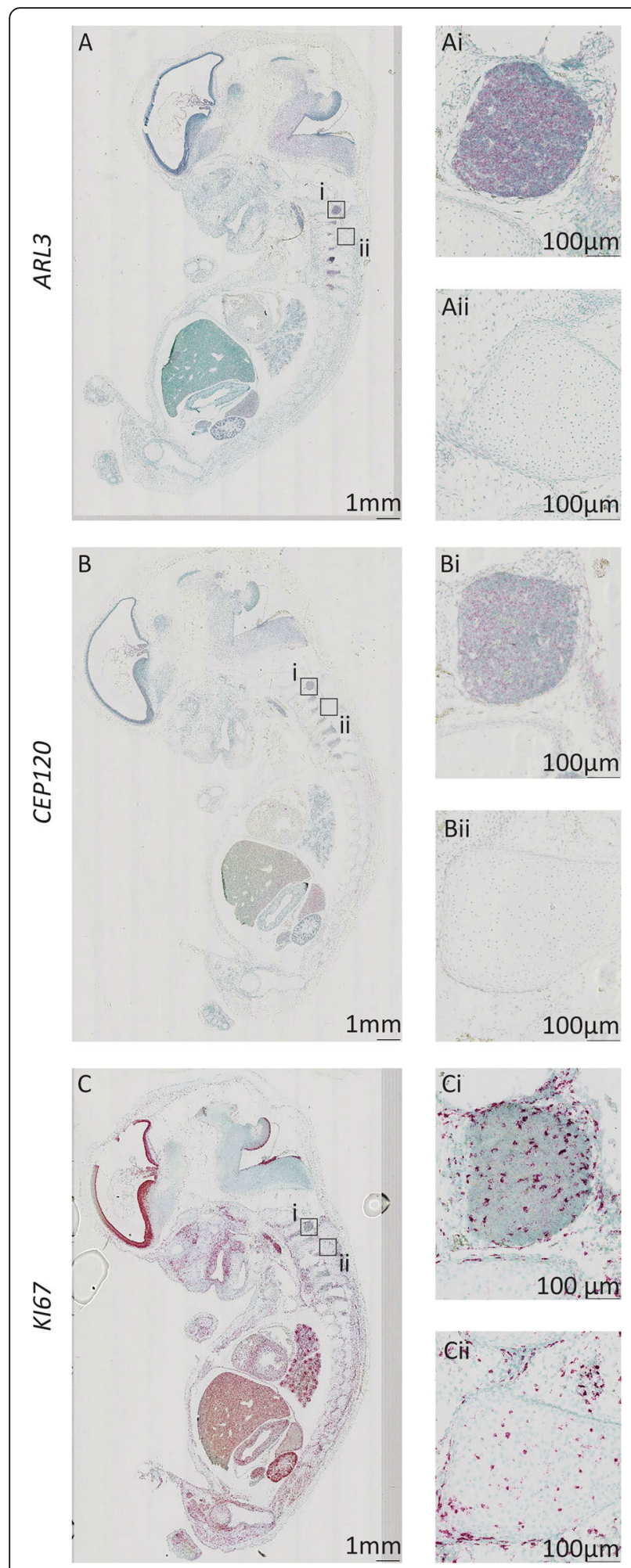

Fig. 4 Expression of ARL3 and CEP120 in the developing human dorsal root ganglia Sagittal sections of 8PCW human embryos stained using RNAscope to show expression of ARL3 (a) (red), CEP120 (b) (red) and KI67 (c) (red) counterstained with Methyl Green. ARL3 and CEP120 expression is shown within the dorasl root ganglia ( $\mathbf{A} \mathbf{i}$ and $\mathbf{B i}$ respectively), whereas surrounding tissue has low level expression of these genes (Aii and $\mathbf{B i i}$. Kl67 expression is seen in the dorsal root ganglia $(\mathbf{C i})$ and surrounding tissues (Cii)

the dorsal root ganglia hints at a role for both genes in primary sensory neurone differentiation. A recurring pattern was the expression of both mRNAs on the luminal facing surface of the cerebral tissue (seen in the choroid plexus and ventricular zones of the cerebral cortex ganglionic eminences, and hindbrain) which could suggest a sensory role for the gene products of both the genes within the cilium of the ventricular lining of the brain.

Expression of ARL3 and CEP120 changes during development notably in the cerebellum and kidney. ARL3 and CEP120 are expressed throughout the cerebellum at $14 \mathrm{PCW}$ however, at 19PCW, ARL3 expression was predominantly in the IGL whereas CEP120 was expressed in the EGL and ML of the cerebellum. This could imply that ARL3 and CEP120 are expressed in different cell populations of the cerebellum, $A R L 3$ in both immature and mature granule cells, and CEP120 in immature, migratory granule cells and ML interneurones [48]. It has been previously reported in mouse studies that Cep120 is required for proliferation of cerebellar neural progenitor cells [28] and is required for correct development of the embryo. Taken with these results, it suggests that CEP120 expression is required for correct development of the cerebellum in humans.

Expression of ARL3 and CEP120 also differed in the developing kidney. The results showed that ARL3 was specifically expressed in cells of the nephrons whereas CEP120 was expressed in the nephrons as well as within cells in the developing renal cortex. This difference in expression could imply that $A R L 3$ has a more sensory/signalling function in luminal structures of the kidney, whereas CEP120 has a more universal role in all cells as it is expressed more ubiquitously throughout the tissue.

The differences in gene expression may reflect the divergent functions of ARL3 and CEP120 proteins (Supplementary Table 2). As ARL3 is a trafficking protein involved in ciliary signalling $[19,49]$, it may only be expressed in actively signalling cells during certain points in development such as nephron progenitors and cells in the IGCL. In contrast, CEP120 is involved in building the centriole, and therefore cilium, [27, 29] and so will be expressed more widely within tissues, especially those with ciliated epithelia $[50,51]$. 


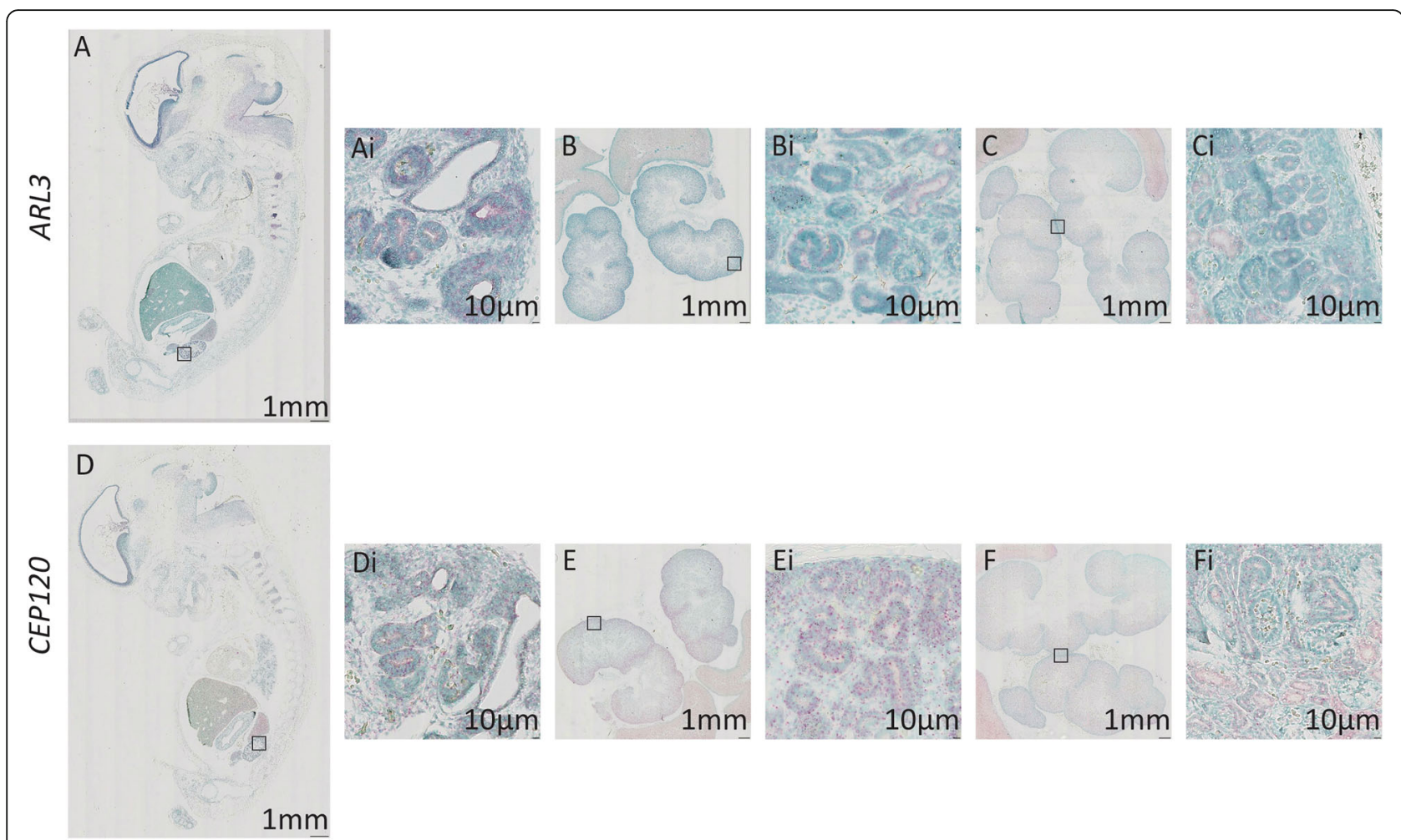

Fig. 5 Expression of ARL3 and CEP120 in the developing human kidney. Sagittal sections of human kidney at 8PCW (a and d), 14PCW (b and e), and 18PCW (c and $\mathbf{f}$ ) stained using RNAscope to show ARL3 expression (a, b, c) (red) and CEP120 (d, e, f) (red) and counterstained with Methyl Green. ARL3 and CEP120 expression at 8PCW (Ai and Di) is seen in the developing kidney cortex. ARL3 and CEP120 expression in the kidney cortex remain the same at 14PCW (Bi and Ei respectively). Ci and Fi shows persistent ARL3 and reduced CEP120 kidney cortex expression at $18 \mathrm{PCW}$

In conclusion, we establish in human embryonic tissue expression patterns of ARL3 and CEP120 during development and provide insights into the wide phenotypic spectrum of mutations affecting ARL3 and CEP120 in humans. These studies will allow further investigations into tissue-specific mechanistic roles of ARL3 and CEP120 in human health and disease.

\section{Supplementary Information}

The online version contains supplementary material available at https://doi. org/10.1186/s12861-020-00231-3.

\section{Additional file 1}

\section{Abbreviations \\ EGL: External granule cell layer; GCL: Ganglion cell layer; HDBR: Human Developmental Biology Resource; IGL: Internal granule cell layer; INL: Inner nuclear layer; IPL: Inner plexiform layer; JATD: Jeune asphyxiating thoracic dystrophy; JSRD: Joubert syndrome and related disorders; MKS: Meckel syndrome; ML: Molecular layer; NFL: Nerve fibre layer; OFD: Oro-facial-digital; ONbL: Outer neuroblastic layer; ONL: Outer nuclear layer; OPL: Outer plexiform layer; PCW: Post-conception weeks; RPE: Retinal pigment epithelium; TCDOE: Tectocerebellar dysraphia with occipital encephalocele}

\section{Authors' contributions}

LP and MB-G analysed and interpreted the data regarding the RNA expression studies. GJC, LAD, SAR and CGM performed data analysis and contributed in writing the manuscript. JAS conceived the project. All authors read and approved the final manuscript.

\section{Funding}

LP is funded by the Medical Research Council Discovery Medicine North Training Partnership. MB-G is funded by Kidney Research UK (ST_001_20171120) and Northern Counties Kidney Research Fund. EM is funded by Kidney Research UK (Paed_RP_20180925). SAR is Kidney Research UK post-doctoral fellow (PDF_003_20151124). CGM and JAS are funded by Kidney Research UK and Northern Counties Kidney Research Fund. The funding bodies had no role in the design of the study and collection, analysis, and interpretation of data nor in the writing of the manuscript.

\section{Availability of data and materials}

All data generated or analysed during this study are included in this published article and its supplementary information files. The datasets used and/or analysed during the current study are available from the corresponding author on reasonable request.

\section{Ethics approval and consent to participate}

This study was conducted with full ethical approval. For human embryonic and foetal tissue samples, the samples were collected with appropriate written maternal consents and ethical approval by the Newcastle and North Tyneside 1 Research Ethics Committee, UK.

\section{Acknowledgements}

Schematic diagrams were created using Biorender.com
Consent for publication

Not applicable. 


\section{Competing interests}

The authors declare that they have no competing interests.

\section{Author details}

'Translational and Clinical Research Institute, Newcastle University, Central Parkway, Newcastle upon Tyne NE1 3BZ, UK. ${ }^{2}$ Biosciences Institute, Newcastle University, Framlington Place, Newcastle upon Tyne NE2 4HH, UK. ${ }^{3}$ The Newcastle Hospitals NHS Foundation Trust, Freeman Road, Newcastle upon Tyne NE7 7DN, UK. ${ }^{4}$ National Institute for Health Research Newcastle Biomedical Research Centre, Newcastle upon Tyne NE4 5PL, UK.

Received: 27 July 2020 Accepted: 11 November 2020 Published online: 09 December 2020

\section{References}

1. Malicdan MC, Vilboux T, Stephen J, Maglic D, Mian L, Konzman D, et al. Mutations in human homologue of chicken talpid3 gene (KIAA0586) cause a hybrid ciliopathy with overlapping features of Jeune and Joubert syndromes. J Med Genet. 2015;52(12):830-9.

2. Travaglini L, Brancati F, Silhavy J, lannicelli M, Nickerson E, Elkhartoufi N, et al. Phenotypic spectrum and prevalence of INPP5E mutations in Joubert syndrome and related disorders. Eur J Human Genet. 2013;21(10):1074-8.

3. Valente EM, Brancati F, Dallapiccola B. Genotypes and phenotypes of Joubert syndrome and related disorders. Eur J Med Genet. 2008;51(1):1-23.

4. Doherty D. Joubert syndrome: insights into brain development, cilium biology, and complex disease. Semin Pediatr Neurol. 2009;16(3):143-54.

5. Paprocka J, Jamroz E. Joubert syndrome and related disorders. Neurol Neurochir Pol. 2012;46(4):379-83.

6. Srivastava S, Ramsbottom SA, Molinari E, Alkanderi S, Filby A, White K, et al. A human patient-derived cellular model of Joubert syndrome reveals ciliary defects which can be rescued with targeted therapies. Hum Mol Genet. 2017;26(23):4657-67

7. Wang SF, Kowal TJ, Ning K, Koo EB, Wu AY, Mahajan VB, et al. Review of Ocular Manifestations of Joubert Syndrome. Genes. 2018;9:12

8. Reiter JF, Leroux MR. Genes and molecular pathways underpinning ciliopathies. Nat Rev Mol Cell Biol. 2017;18(9):533-47.

9. Berbari NF, O'Connor AK, Haycraft CJ, Yoder BK. The primary cilium as a complex signaling center. Curr Biol. 2009;19(13):R526-35.

10. Malicki JJ, Johnson CA. The cilium: cellular antenna and central processing unit. Trends Cell Biol. 2017;27(2):126-40.

11. Christensen ST, Pedersen LB, Schneider L, Satir P. Sensory cilia and integration of signal transduction in human health and disease. Traffic (Copenhagen, Denmark). 2007;8(2):97-109.

12. Hildebrandt F, Otto E. Cilia and centrosomes: a unifying pathogenic concept for cystic kidney disease? Nat Rev Genet. 2005;6(12):928-40.

13. Wheway G, Parry DA, Johnson CA. The role of primary cilia in the development and disease of the retina. Organogenesis. 2014;10(1):69-85.

14. Fansa EK, Wittinghofer A. Sorting of lipidated cargo by the Arl2/Arl3 system. Small GTPases. 2016;7(4):222-30.

15. Alkanderi S, Molinari E, Shaheen R, Elmaghloob Y, Stephen LA, Sammut V et al. ARL3 mutations cause Joubert syndrome by disrupting Ciliary protein composition. Am J Hum Genet. 2018;103(4):612-20.

16. Shaheen R, Schmidts M, Faqeih E, Hashem A, Lausch E, Holder I, et al. A founder CEP120 mutation in Jeune asphyxiating thoracic dystrophy expands the role of centriolar proteins in skeletal ciliopathies. Hum Mol Genet. 2015;24(5):1410-9.

17. Roosing S, Romani M, Isrie M, Rosti RO, Micalizzi A, Musaev D, et al. Mutations in CEP120 cause Joubert syndrome as well as complex ciliopathy phenotypes. J Med Genet. 2016;53(9):608-15.

18. Kahn RA, Der CJ, Bokoch GM. The ras superfamily of GTP-binding proteins: guidelines on nomenclature. FASEB J. 1992;6(8):2512-3.

19. Gotthardt K, Lokaj M, Koerner C, Falk N, Giessl A, Wittinghofer A. A G-protein activation cascade from Arl13B to Arl3 and implications for ciliary targeting of lipidated proteins. eLife. 2015;4.

20. Blacque $\mathrm{OE}$, Perens EA, Boroevich KA, Inglis PN, Li C, Warner A, et al. Functional genomics of the cilium, a sensory organelle. Curr Biol. 2005; 15(10):935-41.

21. Veltel $S$, Gasper R, Eisenacher E, Wittinghofer A. The retinitis pigmentosa 2 gene product is a GTPase-activating protein for Arf-like 3. Nat Struct Mol Biol. 2008;15(4):373-80
22. Evans RJ, Schwarz N, Nagel-Wolfrum K, Wolfrum U, Hardcastle AJ, Cheetham ME. The retinitis pigmentosa protein RP2 links pericentriolar vesicle transport between the Golgi and the primary cilium. Hum Mol Genet. 2010; 19(7):1358-67.

23. Grayson C, Bartolini F, Chapple JP, Willison KR, Bhamidipati A, Lewis SA, et al. Localization in the human retina of the $X$-linked retinitis pigmentosa protein RP2, its homologue cofactor C and the RP2 interacting protein Arl3. Hum Mol Genet. 2002;11(24):3065-74.

24. Schwarz N, Lane A, Jovanovic K, Parfitt DA, Aguila M, Thompson CL, et al. Arl3 and RP2 regulate the trafficking of ciliary tip kinesins. Hum Mol Genet. 2017;26(13):2480-92

25. Hanke-Gogokhia C, Wu Z, Gerstner CD, Frederick JM, Zhang H, Baehr W. Arflike protein 3 (ARL3) regulates protein trafficking and Ciliogenesis in mouse photoreceptors. J Biol Chem. 2016;291(13):7142-55.

26. Schrick JJ, Vogel P, Abuin A, Hampton B, Rice DS. ADP-ribosylation factorlike 3 is involved in kidney and photoreceptor development. Am J Pathol. 2006:168(4):1288-98

27. Mahjoub MR, Xie Z, Stearns T. Cep120 is asymmetrically localized to the daughter centriole and is essential for centriole assembly. J Cell Biol. 2010; 191(2):331-46.

28. Wu C, Yang M, Li J, Wang C, Cao T, Tao K, et al. Talpid3-binding centrosomal protein Cep120 is required for centriole duplication and proliferation of cerebellar granule neuron progenitors. PLoS One. 2014;9(9):e107943.

29. Comartin D, Gupta GD, Fussner E, Coyaud E, Hasegan M, Archinti M, et al. CEP120 and SPICE1 cooperate with CPAP in centriole elongation. Curr Biol. 2013:23(14):1360-6.

30. Lin YN, Wu CT, Lin YC, Hsu WB, Tang CJ, Chang CW, et al. CEP120 interacts with CPAP and positively regulates centriole elongation. J Cell Biol. 2013; 202(2):211-9.

31. Tsai JJ, Hsu WB, Liu JH, Chang CW, Tang TK. CEP120 interacts with C2CD3 and Talpid3 and is required for centriole appendage assembly and ciliogenesis. Sci Rep. 2019;9(1):6037.

32. Xie Z, Moy LY, Sanada K, Zhou Y, Buchman JJ, Tsai LH. Cep120 and TACCs control interkinetic nuclear migration and the neural progenitor pool. Neuron. 2007;56(1):79-93.

33. Wang $H$, Wang MX, Su N, Wang LC, Wu X, Bui S, et al. RNAscope for in situ detection of transcriptionally active human papillomavirus in head and neck squamous cell carcinoma. Journal of visualized experiments : JoVE. 2014;85.

34. Wang F, Flanagan J, Su N, Wang LC, Bui S, Nielson A, et al. RNAscope: a novel in situ RNA analysis platform for formalin-fixed, paraffin-embedded tissues. J Mol Diagnostics. 2012;14(1):22-9.

35. Holtan JP, Teigen K, Aukrust I, Bragadottir R, Houge G. Dominant ARL3related retinitis pigmentosa. Ophthalmic Genet. 2019;40(2):124-8.

36. Strom SP, Clark MJ, Martinez A, Garcia S, Abelazeem AA, Matynia A, et al. De novo occurrence of a variant in ARL3 and apparent autosomal dominant transmission of retinitis Pigmentosa. PLoS One. 2016;11(3):e0150944.

37. Taverna E, Huttner WB. Neural progenitor nuclei IN motion. Neuron. 2010; 67(6):906-14.

38. Hatten ME, Heintz N. Mechanisms of neural patterning and specification in the developing cerebellum. Annu Rev Neurosci. 1995;18:385-408.

39. Chalupa LM, Gunhan E. Development of on and off retinal pathways and retinogeniculate projections. Prog Retin Eye Res. 2004;23(1):31-51.

40. Hendrickson A. Development of Retinal Layers in Prenatal Human Retina. Am J Ophthalmology. 2016;161:29-35 e1.

41. Hoon M, Okawa H, Della Santina L, Wong ROL. Functional architecture of the retina: development and disease. Prog Retin Eye Res. 2014;42:44-84.

42. Krames ES. The role of the dorsal root ganglion in the development of neuropathic pain. Pain Med (Malden, Mass). 2014;15(10):1669-85.

43. Kalcheim C, Barde YA, Thoenen H, Le Douarin NM. In vivo effect of brainderived neurotrophic factor on the survival of developing dorsal root ganglion cells. EMBO J. 1987;6(10):2871-3.

44. Piasecki BP, Silflow CD. The UNI1 and UNI2 genes function in the transition of triplet to doublet microtubules between the centriole and cilium in Chlamydomonas. Mol Biol Cell. 2009;20(1):368-78.

45. Cuvillier A, Redon F, Antoine JC, Chardin P, DeVos T, Merlin G. LdARL 3A, a Leishmania promastigote-specific ADP-ribosylation factor-like protein, is essential for flagellum integrity. J Cell Sci. 2000;113(Pt 11): 2065-74.

46. Li Y, Wei Q, Zhang Y, Ling K, Hu J. The small GTPases ARL-13 and ARL-3 coordinate intraflagellar transport and ciliogenesis. J Cell Biol. 2010;189(6): 1039-51. 
47. Sharma A, Gerard SF, Olieric N, Steinmetz MO. Cep120 promotes microtubule formation through a unique tubulin binding C2 domain. J Struct Biol. 2018;203(1):62-70.

48. Sotelo C. Molecular layer interneurons of the cerebellum: developmental and morphological aspects. Cerebellum (London, England). 2015;14(5):534-56.

49. Ismail SA, Chen YX, Rusinova A, Chandra A, Bierbaum M, Gremer L, et al. Arl2-GTP and Arl3-GTP regulate a GDI-like transport system for farnesylated cargo. Nat Chem Biol. 2011;7(12):942-9.

50. Tucker RW, Pardee AB, Fujiwara K. Centriole ciliation is related to quiescence and DNA synthesis in 3T3 cells. Cell. 1979;17(3):527-35.

51. Pugacheva EN, Jablonski SA, Hartman TR, Henske EP, Golemis EA. HEF1dependent Aurora a activation induces disassembly of the primary cilium. Cell. 2007;129(7):1351-63.

\section{Publisher's Note}

Springer Nature remains neutral with regard to jurisdictional claims in published maps and institutional affiliations.

Ready to submit your research? Choose BMC and benefit from:

- fast, convenient online submission

- thorough peer review by experienced researchers in your field

- rapid publication on acceptance

- support for research data, including large and complex data types

- gold Open Access which fosters wider collaboration and increased citations

- maximum visibility for your research: over $100 \mathrm{M}$ website views per year

At BMC, research is always in progress.

Learn more biomedcentral.com/submissions 